\title{
Attenuated Corynebacterium granulosum
}

National Cancer Institute

\section{Source}

National Cancer Institute. Attenuated Corynebacterium granulosum. NCI Thesaurus.

Code C1644.

A species of Gram-positive, facultatively anaerobic bacteria in the phylum Actinobacteria that are used therapeutically as an immune-stimulant to fight cancer. 